\title{
Prevalence of gastrointestinal diseases in two British national birth cohorts
}

\author{
A G C Ehlin, S M Montgomery, A Ekbom, R E Pounder, A J Wakefield
}

Gut 2003;52:1117-1121

Background: Few studies have investigated the prevalence of multiple gastrointestinal diseases in the general British population.

Aim: To examine the prevalence of Crohn's disease (CD), ulcerative colitis (UC), irritable bowel syndrome (IBS), gall stones (GS), and peptic ulcer disease (PUD).

Subjects: The 1970 British Cohort Study (BCS70) and the National Child Development Study (NCDS) are two one week national birth cohorts born in 1970 and 1958, respectively. All cohort members living in Great Britain were interviewed in 1999/2000.

Methods: The prevalence rates of the five diseases were calculated, and associations with sex and childhood social class were investigated using logistic regression.

See end of article for authors' affiliations Results: At age 30 years, the prevalence rates per 10000 (95\% confidence interval (CI)) in the 1970 and 1958 cohorts, respectively, were: CD 38 (26-49), 21 (13-30); UC 30 (20-41), 27 (18-37); IBS 826 (775-877), 290 (267-330); GS 88 (71-106), 78 (62-94); and PUD 244 (214-273), 229 (201-256). There was a significantly higher proportion with CD $(p=0.023)$ and IBS $(p=0.000)$ in the 1970 cohort compared with the 1958 cohort at age 30 years. Comparing the cohorts in the 1999/ 2000 sweep, UC, GS, and PUD were significantly $(p=0.001, p=0.000, p=0.000)$ more common in the 1958 cohort. There was a statistically significant trend for a higher risk of GS with lower social class in both cohorts combined ( $p=0.027)$.

Conclusion: The study indicates an increasing temporal trend in the prevalence of $C D$ and suggests a period effect in IBS, possibly due to adult life exposures or variation in recognition and diagnosis of IBS.

Accepted for publication 7 February 2003

E ven though only about one third of people with gastrointestinal complaints consult a genera practitioner, ${ }^{1}$ gastrointestinal disorders are estimated to account for approximately $10 \%$ of the work of general practitioners in Britain. ${ }^{1}$ However, few studies have investigated the prevalence of multiple gastrointestinal diseases in the general population. Despite variation in diagnostic criteria for some diseases, prevalence rates and changes in these rates are of interest as they provide information on requirements for treatment and health service use associated with that diagnosis.

Crohn's disease (CD) and ulcerative colitis (UC) are chronic inflammatory bowel diseases (IBD) and some uncertainty remains about their aetiology. Their chronic nature creates lifelong costs and reduces quality of life. ${ }^{2}$ Many studies of the epidemiology of IBD in Great Britain indicate a temporal increase over the last decades of CD in particular, but also of UC. Rubin and colleagues ${ }^{3}$ found a prevalence of $15.6 / 10^{4}$ for CD and 26.8/10 $0^{4}$ for UC in the North Tees Health District in 1995 , including all ages, compared with a prevalence of 3.5/10 for $\mathrm{CD}$ and $6.7 / 10^{4}$ for UC in the same area in 1977 reported by Devlin and colleagues. ${ }^{4}$ There is some inconsistency regarding sex ratio in the prevalence of CD and UC; some reports show no significant difference ${ }^{56}$ while others show a male preponderance in UC and a higher prevalence of females reporting $\mathrm{CD}^{7-10}$ Higher social class has been associated with both $\mathrm{CD}$ and $\mathrm{UC}^{11}{ }^{12}$ but not in all studies. ${ }^{5}{ }^{13}$

The causes and definition of irritable bowel syndrome (IBS) are debated and it has been argued that it is a disease of the mind ${ }^{14}{ }^{15}$ rather than a primary disease of bowel function, or a mix of the two. ${ }^{16}$ Studies of the epidemiology of IBS have consistently shown that the prevalence of IBS is greater in women compared with men. Österberg and colleagues ${ }^{17}$ reported prevalence rates of $5.0-6.6 \%$ for men aged $31-40$ years and

$10.5-12.9 \%$ for women aged 31-40 years. Jones and Lydeard ${ }^{18}$ found a prevalence of $24300 / 10^{5}$ for women and $18700 / 10^{5}$ for men. Privileged living circumstances in early life has been associated with a higher risk of IBS. ${ }^{19}$

There are two main groups of gall stones (GS): cholesterol stones and pigment stones. Cholesterol stones are the most common and have been associated with several risk factors. ${ }^{20-22}$ Prevalence rates of GS have been reported to be $1.8 \%$ and $4.8 \%$ at age 30 years for men and women, respectively, and $1.5 \%$ and $6.1 \%$ at age 40 years. ${ }^{23}$

The precise mechanism of the pathogenesis of peptic ulcer disease (PUD) is still uncertain even though it has been shown to involve Helicobacter pylori. ${ }^{24} 25$

The lifetime prevalence of PUD is approximately 500-1000/ $10^{4}$ in developed countries. ${ }^{26}$ There has been a considerable decline in PUD over the last decade and the sex difference in risk has also decreased ${ }^{26}$ The prevalence rates for men seem to have decreased whereas they have increased for women: sex ratios of approximately $1: 1$ have been reported in the USA and Norway $^{27}{ }^{28}$ while a Danish study reported a male to female prevalence ratio of $2.2: 1.0 .^{29}$

This study reports the prevalence of CD, UC, IBS, GS, and PUD in 1999/2000 in two general population samples in Great Britain, based on self reported diagnoses obtained during a personal interview. The samples are two birth cohort studies following all births in the weeks 3-9 March 1958 and 5-11 April 1970. The prevalence of diseases with onset by age 30 years was compared between the cohorts. Associations with

Abbreviations: CD, Crohn's disease; UC, ulcerative colitis; IBS, irritable bowel syndrome; GS, gall stones; PUD, peptic ulcer disease; BCS70, 1970 British cohort study; NCDS, National Child Development Study. 
social class in childhood as a marker of material and cultural circumstances are reported.

\section{METHODS}

\section{Study population}

Data were from two British birth cohort studies, the National Child Development Study (NCDS) and the 1970 British Cohort Study (BCS70). NCDS is an ongoing longitudinal study including all those living in Great Britain who were born between 3 and 9 March 1958. NCDS started with approximately 17000 live births in 1958, called the Perinatal Mortality Survey. ${ }^{30}$ The entire cohort was followed up at 7, 11, $16,23,33$, and 42 years of age. BCS70 is a similar longitudinal study of those living in Great Britain born during the week 5-11 April 1970. BCS70 began as the British Births Survey and included about 17000 births in England, Scotland, Wales, and Northern Ireland; children born in Northern Ireland were subsequently dropped from the cohort. Immigrants who were born in the week 5-11 April were added to the study in the five year follow up. The entire cohort was followed up at 5, 10, 16, 26 , and 30 years of age. Despite some loss, the cohorts remain representative, although there is some underrepresentation of the most disadvantaged groups. ${ }^{31}$

The target for the 1999/2000 sweep, all cohort members excluding previous deaths, refusals, and those permanently emigrated, was 16460 in the 1958 cohort and 16695 in the 1970 cohort. A total of 247 cohort members in the 1958 cohort and 109 in the 1970 cohort were identified during the survey year as having died since the previous survey. We are not routinely informed of deaths among emigrants and recent refusals. At least one survey instrument was partially completed for 11419 (70.4\% of the target, excluding recent deaths) in the 1958 cohort and for 11261 cohort members $(67.9 \%$ of the target, excluding recent deaths) in the 1970 cohort. ${ }^{32}$

The 1999/2000 surveys of both cohorts were conducted via computer aided personal interviews performed by professional interviewers, and included a total of 22680 cohort members. Cohort members were asked whether they had, ever had, or been told they had any of the following diseases: peptic, duodenal or gastric ulcer; gall stones; irritable bowel syndrome; ulcerative colitis; Crohn's disease, or none of these. They were also asked at what age they first had the disease. Where disease onset was reported as being in childhood, confirmatory evidence was sought from the contemporaneous childhood records of diagnoses and the age of onset taken from these. A total of 22586 cohort members had complete gastrointestinal data: 11261 BCS70 (1970) cohort members at 30 years of age ( 5443 males and 5768 females) and 11375 NCDS (1958) cohort members at 42 years of age (5601 males and 5774 females).

In both cohorts, the social class of the cohort member's father or mother's husband was recorded prospectively at birth, using the Register General's classification of occupation. Social class was divided into I, II, III non-manual, III manual, IV, V, unsupported mothers, other, and not known. The "other" category included the cohort member's father or mother's husband who was unemployed, sick, a student, dead, away, or retired. Immigrants who were subsequently recruited lacked the social class variable at birth and were therefore excluded from the analysis of social class.

The BCS70 IBD data were validated by comparison with data collected at age 26 years where the diagnosis was confirmed by histology and physician reports. ${ }^{5}$ Based on age of diagnosis and previous physician confirmation at age 26 years, adjustments were made in a total of nine patients, of which five patients, who reported both CD and UC, were identified as having a diagnosis of $\mathrm{CD}$, three patients who reported both $\mathrm{CD}$ and UC were identified as having a diagnosis of UC, and one patient who reported having UC was reclassified as not having a diagnosis of IBD. The adjustments made no statistically significant difference to the reported comparisons.

\section{Statistical analysis}

Logistic regression was used to investigate the relationships between the prevalence of the gastrointestinal diseases and year of birth, social class at birth, and sex. Pearson's $\chi^{2}$ test was used when comparing the prevalence of the diseases and $95 \%$ confidence interval (CI) for the population proportion ${ }^{33}$ was used to calculate the confidence intervals around the prevalence. The social class variable was modelled as a series of dummy variables but when trend was measured, this was modelled as an ordinary categorical variable, estimating trend across the categories. The categories "unsupported mothers", "other", and "not known" were excluded from the trend analysis. Age of onset was used to age standardise the prevalence rates: disease onset up to age 30 years was estimated in the 1958 cohort for comparison with the 1970 cohort at 30 years of age. SPSS for windows, version 10.1.0, was used for all analyses.

\section{RESULTS}

At least one survey instrument was partially completed for 11 419 cohort members $(70.4 \%$ of the target, excluding recent deaths) in the 1958 cohort and for 11261 cohort members (67.9\% of the target, excluding recent deaths) in the 1970 cohort.

The prevalence of the diseases by cohort and sex is shown in table 1 .

\section{Crohn's disease}

Median age of onset of CD was 21 years (range 14-29; mean $21.49 ; 95 \%$ CI of mean 20.49-23.17) in the 1970 cohort and 26 years $(12-40 ; 26.81 ; 24.50-29.13)$ in the 1958 cohort.

The prevalence of CD was $37.5 / 10^{4}$ (95\% CI 26.2-48.8) in the 1970 cohort at 30 years of age, $21.1 / 10^{4}(12.7-29.5)$ in the 1958 cohort at 30 years of age, and $32.5 / 10^{4}(22.1-43.0)$ in the 1958 cohort at 42 years of age. There was a significantly higher proportion with CD in the 1970 cohort at 30 years of age compared with the 1958 cohort at the same age (odds ratio (OR) $1.78,95 \%$ CI $1.08-2.94 ; p=0.023$ ). There was a higher proportion $(\mathrm{p}=0.530)$ with $\mathrm{CD}$ in the 1970 cohort at age 30 years compared with the 1958 cohort at 42 years of age but this was not statistically significant. There was no significant association between social class at birth (linear trend: cohorts combined, $\mathrm{p}=0.566 ; 1970$ cohort, $\mathrm{p}=0.704 ; 1958$ cohort, $\mathrm{p}=0.628$ ) or sex (combined, $\mathrm{p}=0.757 ; 1970$ cohort, $\mathrm{p}=0.85 \mathrm{l}$; 1958 cohort, $\mathrm{p}=0.797$ ) and $\mathrm{CD}$.

\section{Ulcerative colitis}

Median age of onset of UC was 23 years $(15-29 ; 22.50 ; 21.06-$ $23.94)$ in the 1970 cohort and 30 years (19-41; 30.63; 29.08-32.17) in the 1958 cohort.

The prevalence of UC was $30.3 / 10^{4}(20.1-40.5)$ in the 1970 cohort at 30 years of age, $27.3 / 10^{4}(17.7-36.8)$ in the 1958 cohort at 30 years of age, and 58.9/10 $0^{4}(44.8-73.0)$ in the 1958 cohort at 42 years of age. A comparison of the prevalence of UC in the 1970 cohort with the 1958 cohort at 30 years of age showed no significant difference $(p=0.666)$. There was a significantly $(p=0.001)$ higher proportion of UC in the 1958 cohort at age 42 years compared with the 1970 cohort at age 30 years. There was no statistically significant relationship with social class at birth or sex in the cohorts combined or individually.

\section{Irritable bowel syndrome}

One member in the 1970 cohort with a diagnosis of IBS reported onset of symptoms at age five years. Abdominal pain and other recurring gastrointestinal symptoms were recorded in the childhood records but without a diagnosis of IBS. As 
Table 1 Prevalence of gastrointestinal diseases in two British birth cohorts

\begin{tabular}{|c|c|c|c|}
\hline & \multicolumn{3}{|l|}{ Rate; prevalence per $10000(95 \% \mathrm{Cl})$} \\
\hline & BCS70-30 years of age & NCDS -30 years of age & NCDS -42 years of age \\
\hline \multicolumn{4}{|c|}{ Crohn's disease } \\
\hline Male & $21 / 5443 ; 38.6(22.1,55.1)$ & $15 / 5601 ; 26.8(13.2,40.3)$ & $19 / 5601 ; 33.9(18.7,49.2)$ \\
\hline Female & $21 / 5768 ; 36.4(20.9,52.0)$ & $9 / 5774 ; 15.6(5.4,25.8)$ & $18 / 5774 ; 31.2(16.8,45.6)$ \\
\hline Total & $42 / 11211 ; 37.5(26.2,48.8)$ & $24 / 11375 ; 21.1(12.7,29.5)$ & $37 / 11375 ; 32.5(22.1,43.0)$ \\
\hline \multicolumn{4}{|c|}{ Ulcerative colitis } \\
\hline Male & $13 / 5443 ; 23.9(10.9,36.9)$ & $15 / 5601 ; 26.8(13.2,40.3)$ & $30 / 5601 ; 53.6(34.4,72.7)$ \\
\hline Female & $21 / 5768 ; 36.4(20.9,52.0)$ & $16 / 5774 ; 27.7(14.1,41.3)$ & $37 / 5774 ; 64.1(43.5,84.7)$ \\
\hline Total & $34 / 11211 ; 30.3(20.1,40.5)$ & $31 / 11375 ; 27.3(17.7,36.8)$ & $67 / 11375 ; 58.9(44.8,73.0)$ \\
\hline \multicolumn{4}{|c|}{ Irritable bowel syndrome } \\
\hline Male & $195 / 5443 ; 358.3(309.9,407.6)$ & $91 / 5601 ; 162.5(129.4,195.6)$ & $273 / 5601 ; 487.4(431.0,543.8)$ \\
\hline Female & $731 / 5768 ; 1267.3(1181.5,1353.2)$ & $249 / 5774 ; 431.2(378.8,483.7)$ & $686 / 5774 ; 1188.0(1104.6,1271.6)$ \\
\hline Total & $926 / 11211 ; 826.0(775.0,876.9)$ & $340 / 11375 ; 289.9(267.6,330.2)$ & $959 / 11375 ; 843.1(792.0,894.1)$ \\
\hline \multicolumn{4}{|l|}{ Gall stones } \\
\hline Males & $20 / 5443 ; 36.7(20.7,52.8)$ & $15 / 5601 ; 26.8(13.2,40.3)$ & $46 / 5601 ; 82.1(58.5,105.8)$ \\
\hline Females & $79 / 5768 ; 137.0(107.0,167.0)$ & $74 / 5774 ; 128.2(99.1,157.2)$ & $219 / 5774 ; 379.3(330.0,428.6)$ \\
\hline Total & $99 / 11211 ; 88.3(71.0,105.6)$ & $89 / 11375 ; 78.2(62.0,94.4)$ & $265 / 11375 ; 233.0(205.2,260.7)$ \\
\hline \multicolumn{4}{|c|}{ Peptic ulcer disease } \\
\hline Male & $173 / 5443 ; 317.8(271.2,364.4)$ & $182 / 5601 ; 324.9(278.5,371.4)$ & $309 / 5601 ; 551.7(491.9,611.5)$ \\
\hline Female & $100 / 5768 ; 173.4(139.7,207.1)$ & $78 / 5774 ; 135.1(105.3,164.9)$ & 192/5774; 332.5 (286.2, 378.8) \\
\hline Total & $273 / 11211 ; 243.5(214.4,272.6)$ & $260 / 11375 ; 228.6(201.1,256.0)$ & $501 / 11375 ; 440.4(402.7,478.2)$ \\
\hline
\end{tabular}

BCS70, 1970 British cohort study; NCDS, National Child Development Study; 95\% Cl, 95\% confidence interval.

IBS, but no other chronic disease, was diagnosed in this patient several years later, we coded the age of IBS onset as five years of age.

Median age of onset of IBS was 24 years $(5-30 ; 22.63$; $22.31-22.95)$ in the 1970 cohort and 35 years $(16-41$; 32.88 ; $32.46-33.30$ ) in the 1958 cohort.

The prevalence of IBS was $826.0 / 10^{4}(775.0-876.9)$ in the 1970 cohort and 289.9/104 (267.6-330.2) in the 1958 cohort at 30 years of age. There was a significantly higher proportion of IBS in the 1970 cohort at 30 years of age compared with the 1958 cohort at the same age (unadjusted odds ratio $2.92,95 \%$ CI 2.57-3.32; $\mathrm{p}=0.000$ ). There were similar proportions with IBS in the 1970 cohort at 30 years of age and in the 1958 cohort at 42 years of age. There were significantly more women than men reporting IBS in the 1970 cohort at 30 years of age and in the 1958 cohort both at age 30 years and 42 years ( 1970 cohort, $\mathrm{p}=0.000 ; 1958$ cohort at age $30, \mathrm{p}=0.000 ; 1958$ cohort at age 42 years, $p=0.000$ ). There was no statistically significant association between IBS and social class at birth in either cohort ( 1970 cohort, $p=0.173 ; 1958$ cohort, $p=0.731$ ) or when both were combined $(\mathrm{p}=0.501)$.

\section{Gall stones}

Median age of onset of GS was 25 years (14-30; 24.14; 23.29$24.99)$ in the 1970 cohort and 34 years (15-41; 32.15; $31.30-33.00$ ) in the 1958 cohort.

The prevalence of GS was $88.3 / 10^{4}(71.0-105.6)$ in the 1970 cohort at 30 years of age, $78.2 / 10^{4}(62.0-94.4)$ in the 1958 cohort at 30 years of age, and 233.0/10 $(205.2-260.7)$ in the 1958 cohort at 42 years of age. There was no statistically significant difference $(p=0.405)$ in the prevalence of GS comparing the 1970 cohort and the 1958 cohort, both at 30 years of age. There was a significantly $(p=0.000)$ higher proportion of GS in the 1958 cohort at age 42 years compared with the 1970 cohort at age 30 years. Significantly more women than men reported GS in both cohorts individually (1970 cohort, $\mathrm{p}=0.000 ; 1958$ cohort, $\mathrm{p}=0.000)$ and when combined $(p=0.000)$. The trend across social classes $(I-V)$ was statistically significant (unadjusted odds ratio 1.11 , 95\% CI 1.01$1.22 ; \mathrm{p}=0.027$ ) for the cohorts combined but not individually (BCS70, $p=0.116$; NCDS, $p=0.175$ ).

\section{Peptic ulcer disease}

Median age of onset of PUD was 24 years (15-29; 23.39; $22.93-23.85)$ in the 1970 cohort and 30 years $(14-41 ; 29.75$; 29.06-30.43) in the 1958 cohort.

The prevalence of PUD was $243.5 / 10^{4}(214.4-272.6)$ in the 1970 cohort at 30 years of age, $228.6 / 10^{4}(201.1-256.0)$ in the 1958 cohort at 30 years of age, and $440.4 / 10^{4}(402.7-478.2)$ in the 1958 cohort at 42 years of age. There was no statistically significant difference $(p=0.460)$ in the prevalence of PUD between the two cohorts at age 30 years. There was a significantly $(p=0.000)$ higher proportion of PUD in the 1958 cohort at age 42 years compared with the 1970 cohort at age 30 years. There were significantly fewer women than men reporting PUD (unadjusted odds ratio $0.57,95 \%$ CI $0.49-0.66$; $p=0.000$ ) in the cohorts combined. The trend across social classes (I-V) at birth was statistically significant in the 1958 cohort at 30 years of age (unadjusted odds ratio 1.13, 95\% CI 1.01-1.26; $\mathrm{p}=0.029$ ) but not in the 1970 cohort at the same age $(\mathrm{p}=0.068)$.

\section{Gastrointestinal diseases in both birth cohorts}

We found that $8.8 \%$ (8.3-9.3\%) of cohort members in the 1970 cohort developed a chronic and relapsing gastrointestinal disease (IBD or IBS) by age 30 years. In the same cohort, where all gastrointestinal diseases were considered, $11.6 \%$ (11.0$12.1 \%$ ) of the cohort members had some form of gastrointestinal disease by age 30 years. In the 1958 cohort, 9.1\% (8.6-9.7\%) of cohort members had developed a chronic and relapsing gastrointestinal disease by age 42 years. By 42 years of age, $14.6 \%(14.0-15.3 \%)$ of cohort members in the 1958 cohort had some form of gastrointestinal disease.

\section{DISCUSSION}

This study investigated the prevalence of multiple gastrointestinal diseases and disease specific sex ratios using British population based data from two nationally representative British birth cohorts. We investigated social class at birth as it is associated with exposure patterns during childhood and beyond, ${ }^{34} 35$ including exposures that may be relevant to some gastrointestinal diseases. ${ }^{36-39}$

The IBD data were validated by comparison with the 1970 cohort data collected at age 26 years, where diagnoses were confirmed by histology and physician reports. ${ }^{5}$ Alterations 
made to the data did not significantly change the results. This suggests that the unvalidated data from the 1958 cohort are likely to be similarly accurate. Validation of the other diseases was not possible but we are confident in the diagnosis of GS as it is unlikely that patients with GS would misreport this; however, patients with subclinical or undiagnosed disease would not be identified. The criteria used to diagnose IBS might vary between subjects and cohorts: IBS is often a diagnosis of exclusion. The treatment and management of PUD has changed considerably over the last 30 years from dietary alterations to gastric acid suppression with $\mathrm{H}_{2}$ receptor antagonists ${ }^{40}$ or proton pump inhibitors, ${ }^{41}$ and now eradication of $\mathrm{H}$ pylori infection. ${ }^{42}$ Changes in treatment of PUD have influenced the policies for detecting PUD: a "test and treat" strategy, a test for $H$ pylori and eradication therapy, was recently recommended for those younger than 45 years of age by the European Helicobacter Pylori Study Group. ${ }^{43}$ It is possible that these changes have affected the diagnosis of PUD in the two cohorts. Despite variation in diagnostic criteria for some diseases, prevalence rates and changes in these rates are of interest as they provide information on trends in requirements for treatment and health service use associated with these diagnoses.

The prevalence of CD found in this study was higher than that in earlier studies in Britain in 1977, 1980, and 1995. ${ }^{3474}$ Birth cohort effects have previously been found for CD and UC in Sweden for those born in 1945-1954 and 1946-1950 45 whereas other studies, investigating CD in Sweden (19631987) and in Britain (1931-1985), have not been able to demonstrate any difference in prevalence of $\mathrm{CD}$ between different cohorts. ${ }^{46}{ }^{47}$ Comparison of the two cohorts is consistent with an increasing temporal trend, suggesting variations in pattern of some environmental exposures. The risk of CD has been associated with improved material conditions, ${ }^{38}{ }^{39}$ and some specific exposures associated with this may explain these differences. The comparable prevalence of UC in the two cohorts at 30 years of age implies a similar overall prevalence of UC in the two cohorts. The UC:CD ratio has changed however. It has been suggested that changes in pattern of some exposures may alter the ratio of CD to UC. ${ }^{48}{ }^{49}$ The prevalence of UC in this study was higher than that found in some earlier studies in Britain in 1995 and in Minnesota in 1991. ${ }^{3440}$

Findings concerning sex ratios in CD and UC have been inconsistent, where some studies have reported no difference, ${ }^{46}{ }^{51}$ some have observed a higher prevalence of CD in women, ${ }^{7-9} 475253$ and others a higher prevalence of UC in men. ${ }^{50}{ }^{54}$ Paediatric CD tends to show a higher prevalence in boys compared with girls. ${ }^{55}{ }^{56}$ We found no statistically significant sex difference in CD or UC. Higher social class at birth has previously been associated with $\mathrm{CD}$ and $\mathrm{UC}^{11}{ }^{12}$ but we found no statistically significant relationship. It has previously been suggested $^{5}$ that a homogenisation of the pattern of exposure across the classes of risk factors for CD and UC might be responsible for the lack of association between social class and IBD found in some recent studies. ${ }^{513}$ Both CD and UC have been associated with an increased risk of colorectal cancer ${ }^{57-60}$ and with some extracolonic malignancies, ${ }^{59-61}$ and an increase of IBD would increase the health cost burden and would also entail an increased risk of IBD related malignancies.

We found prevalence rates for IBS within the broad range reported by earlier studies. ${ }^{17}{ }^{18} 62$ The study conforms to previous observations of a greater prevalence of IBS in women than in men. ${ }^{17186263}$ The similar prevalence of IBS in the 1970 cohort and the 1958 cohort at the single time point, 1999/2000, and the higher prevalence of IBS in the 1970 cohort compared with the 1958 cohort both at 30 years of age suggest a period effect, where current adult life exposures are important. Alternatively, it is now a common diagnosis applied equally to the two populations in the 1999/2000 sweep. This study found no statistically significant difference in risk of IBS by social class at birth, unlike other studies. ${ }^{19}$ Social class at birth may be a poor indicator of the relevant risks.
The prevalence of GS was lower than that in other studies for similar age groups. ${ }^{236465}$ However, our results are in line with Jørgensen's reported prevalence rates according to awareness of the disease: $0.7 \%$ and $1.1 \%$ in men and women, respectively, at age 30 years, and $0.4 \%$ and $2.6 \%$ in men and women, respectively, at age 40 years. It has been well documented that women are at higher risk of developing GS. ${ }^{23}{ }^{64}{ }^{66}$ There was a statistically significant trend across social classes at birth $(\mathrm{I}-\mathrm{V})$ in the cohorts combined where the lower classes were associated with a higher risk of GS.

The prevalence of PUD is consistent with earlier reports. ${ }^{26}$ There was no statistically significant difference in the prevalence of PUD between the two cohorts both at 30 years of age. The proportion of cohort members reporting a diagnosis of PUD may be artificially inflated by those with conditions such as functional dyspepsia or gastro-oesophageal reflux incorrectly labelled as PUD. It is possible that this inflation may mask some changes in prevalence that might have been expected resulting from a declining prevalence of $H$ pylori. The male predominance seen in both cohorts is consistent with earlier findings. ${ }^{27-29}$ PUD has been associated with lower social class $^{67}{ }^{68}$ and this study found a statistically significant association between PUD at age 30 and 42 years with lower social classes in the 1958 cohort, but not in the 1970 cohort at age 30 years. Relevant exposures associated with social class in the 1958 cohort might not be linked with class in the 1970 cohort. Homogenisation of pattern of exposures across the social classes, as previously suggested for $\mathrm{CD}$ and $\mathrm{UC}^{5}$ might be responsible for the lack of association between PUD and social class in the younger cohort.

The high prevalence of gastrointestinal diseases, $11.6 \%$ in the 1970 cohort and $14.6 \%$ in the 1958 cohort at age 30 and 42 years, respectively, and particularly the chronic diseases, $8.8 \%$ in the 1970 cohort and $9.1 \%$ in the 1958 cohort at age 30 and 42 years, respectively, has significant implications for health service resources. The high prevalence of IBD is of particular concern given the lifelong cost of care and increased risk of cancer.

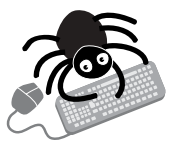

Data on the prevalence of Crohn's disease, ulcerative colitis, irritable bowel syndrome, gall stones, and peptic ulcer disease by social class at birth in both cohorts can be found in supplementary tables 1-5 on the Gut website (www.gutjnl.com/ supplemental).

\section{ACKNOWLEDGEMENT}

Thanks are due to the Centre for Longitudinal Studies, University of London, who supplied the data, to the Hayward Trust who provided financial support, and to Visceral who also supported this research.

\section{Authors' affiliations}

A G C Ehlin, S M Montgomery, A Ekbom, Enheten för Klinisk Epidemiologi, Institutionen för medicin vid Karolinska Sjukhuset, Karolinska Institutet, Stockholm, Sweden

R E Pounder, A J Wakefield, IBD Study Group, Department of Medicine, Royal Free and University College Medical School, London, UK

\section{REFERENCES}

1 Jones RH. Clinical economics review: gastrointestinal disease in primary care. Aliment Pharmacol Ther 1996;10:233-9.

2 Casati J, Toner BB. Psychosocial aspects of inflammatory disease. Biomed Pharmacother 2000;54:388-93.

3 Rubin GP, Hungin AS, Kelly P, et al. Epidemiological features of inflammatory bowel disease in the north of England. Gastroenterology 1995; 110:A1004.

4 Devlin HB, Datta D, Dellipiani. The incidence and prevalence of inflammatory bowel disease in North Tees Health District. World J Surg 1980:4:183-93.

5 Montgomery SM, Morris DL, Thompson NP, et al. Prevalence of inflammatory bowel disease in British 26 year olds: National Longitudinal Birth Cohort. BM 1998;316:1058-9. 
6 Probert CSJ, Jayanthi V, Pinder D, et al. Epidemiologic-study of ulcerative proctocolitis in Indian migrants and the indigenous population of Leicestershire. Gut 1992:33:687-93.

7 Lee FI, Costello FT. Crohn's disease in Blackpool-incidence and prevalence 1968-80. Gut 1985;26:274-8

8 Ekbom A, Helmick C, Zack M, et al. The epidemiology of inflammatory bowel disease: a large, population-based study in Sweden. Gastroenterology 1991;100:350-8.

9 Fellows IW, Freeman JG, Holmes GKT. Crohn's disease in the city of Derby, 1951-85. Gut 1990;31:1262-5.

10 Gollop JH, Phillips SF, Melton LI III, et al. Epidemiologic aspects of Crohn's disease: a population based study in Olmsted County, Minnesota, 1943-1982. Gut 1988;29:49-56.

11 Keighley A, Miller DS, Hughes AO, et al. The demographic and social characteristics of patients with Crohn's disease in the Nottingham area. Scand J Gastroent 1976;1I:293-6.

12 Mayberry JF, Dew M, Morris JS, et al. An audit of Crohn's disease in a defined population. J Coll Physicians Lond 1983;17:196-8.

13 Bernstein CN, Kraut A, Blanchard JF, et al. The relationship between inflammatory bowel disease and socioeconomic variables. Am J Gastroenterol 2001:96:2117-25.

14 Tallay NJ, Boyce PM, Jones M. Is the association between irritable bowel syndrome and abuse explained by neuroticism? A population based study. Gut 1998;42:47-53.

15 Woodman CL, Breen K, Noyes R, et al. The relationship between irritable bowel syndrome and psychiatric illness. Psychosomatics 1998;39:45-54.

16 Gwee KA, Leong YL, Graham C, et al. The role of psychological and biological factors in postinfective gut dysregulation. Gut 1999;44:400-6.

17 Österberg E, Blomquist L, Krakau I, et al. A population study of irritable bowel syndrome and mental health. Scand J Gastroenterol 2000;35:264-8

18 Jones R Lydeard S. Irritable bowel syndrome in the general population. BM 1992;304:87-90.

19 Mendall MA, Kumar D. Antibiotic use, childhood affluence and irritable bowel syndrome (IBS). Eur J Gastroenterol Hepatol 1998;10:59-62.

20 Erlinger S. Gallstones in obesity and weight loss. Eur J Gastroenterol Hepatol 2000;1 2: 1347-52.

21 Everson GT, McKinley C, Kern F. Mechanism of gallstone formation in women- effects of exogenous estrogen (premarin) and dietary cholesterol on hepatic lipid-metabolism. J Clin Invest 1991;87:237-46.

22 Chapman BA, Wilson IR, Frampton CM, et al. Prevalence of gallbladder disease in diabetes mellitus. Dig Dis Sci 1996;41:2222-8.

23 Jørgensen T. Prevalence of gallstones in a Danish population. Am J Epidemiol 1987; 126:912-21

24 Veldhuyzen van Zanten SJO, Sherman PM. Helicobacter pylori infection as a cause of gastisis, duodenal ulcer, gastric ulcer and nonulcerdyspepsia: a systematic Overview. Can Med Assoc J 1994; 150: 177-85.

25 Blum AL. Helicobacter pylori and peptic ulcer disease. Scand J Gastroenterol 1996:31:24-7.

26 Kreiss C, Blum AL. Epidemiology and risk factors of peptic ulcer. Chirurg $2001 ; 67: 7-13$

27 Kurata JH, Haile BM, Elashoff JD. Sex differences in peptic ulcer disease. Gastroenterology 1985;88:96-100

28 Bernersen B, Johnsen R, Straume B, et al. Towards a true prevalence of peptic ulcer: the Sorreisa Gastrointestinal Disorder Study. Gut 1990:31:989-92.

29 Rosenstock SJ, Jorgensen T. Prevalence and incidence of peptic-ulcer disease in a Danish County-a prospective cohort study. Gut 1995;36:819-24

30 Butler NR, Bonham DG. Perinatal Mortality: the First Report of the 1958 British Perinatal Mortality Survey. Edinburgh: Livingstone, 1963.

31 Bynner JM, Ferri E, Shepherd P. Twenty-something in the 1990s. Aldershot: Ashgate, 1998.

32 Ferri E. Life at 33: the Fifth Follow-up of the National Child Development Study. London: National Children's Bureau, 1993.

33 Petrie A. Estimation. Lecture Notes on Medical Statistics, 2nd edn. Oxford: Blackwell Scientific publications, 1987.

34 Holland $\mathbf{P}$, Berney LR, Blane D, et al. Life course accumulation of disadvantage: childhood health and hazard exposures during adulthood. Soc Sci Med 2000;50: 1285-95.

35 Van der Luchts F, Groothoff J. Social inequalities and health among children aged 10-11 in the Netherlands: cause and consequences. Soc Sci Med 1995;40:1305-11.

36 Sitas F, Forman D, Yarnell JW, et al. Helicobacter pylori infection rates in relation to age and social class in a population of Welsh men. Gut $1991 ; 32: 25-8$
37 Malaty HM, Graham DY. Importance of Childhood socioeconomic status on the current prevalence of Helicobacter pylori infection. Gut 1994:35:742-5.

38 Gent $\mathbf{A E}$, Hellier MD, Grace RH, et al. Inflammatory bowel disease and domestic hygiene in infancy. Lancet 1994;343:766-7.

39 Blanchard JF, Bernstien CN, Wajda A, et al. Small-area variations and sociodemographic correlates for the incidence of Crohn's disease and ulcerative colitis. Am J Epidemiol 2001;154:328-35.

40 Black JW, Duncan WAM, Durant CJ, et al. Definition and antagonism of histamine $\mathrm{H} 2$-receptors. Nature 1972:236:385-90.

41 Fellenius E, Berglindh T, Sachs G, et al. Substituted benzimidazoles inhibit gastric acid secretion by blocking $(\mathrm{H}++\mathrm{K}+)$ ATPase. Nature 1981;290:159-61

42 Labenz J, Borsch G. Highly significant change of the clinical course of relapsing and complicated peptic ulcer disease after cure of Helicobacter pylori infection. Am J Gastroenterol 1994:89:1785-8.

43 European Helicobacter Pylori Study Group. Current european concepts in the management of Helicobacter pylori infection. The Maastricht Consensus Report. Gut 1997;41:8-13.

44 Rubin GP, Hungin APS, Kelly PJ, et al. Inflammatory bowel disease: epidemiology and management in an English general practice population. Aliment Pharmacol Ther 2000;14:1553-9.

45 Lapidus A, Bernell O, Hellers $G$, et al. Incidence of Crohn's disease in Stockholm County 1955-1989. Gut 1997:41:480-6.

46 Lindberg $\mathbf{E}$, Jarnerot $G$. The incidence of Crohn's disease is not decreasing in Sweden. Scand J Gastroenterol 1991;26:495-500.

47 Rose JDR, Roberts GM, Williams G, et al. Cardiff Crohn's Disease Jubilee: the incidence over 50 years. Gut 1988;29:346-51.

48 Montgomery SM, Pounder RE, Wakefield AJ. Infant mortality and the incidence of inflammatory bowel disease. Lancet 1997:349:472-3.

49 Montgomery SM. The silent pathogenesis of inflammatory bowel disease. Inflamm Bowel Dis Monit 1999;1:34-8

50 Loftus EV, Silverstein MD, Sandborn WJ, et al. Ulcerative colitis in Olmsted County, Minnesota, 1940-1993: incidence, prevalence, and survival. Gut 2000;46:336-43.

51 Haug K, Schrumpf E, Fluge G, et al. Epidemiology of Crohn's disease in Western Norway. Gastroenterology 1989;24:1271-5.

52 Munkholm $\mathbf{P}$, Langholz $\mathrm{E}$, Nielsen $\mathrm{OH}$, et al. Incidence and prevalence of Crohn's disease in the County of Copenhagen, 1962-87-A sixfold increase in incidence. Scand J Gastroenterol 1992;27:609-14.

53 Kyle J. Crohn's Disease in the Northeastern and Northern Isles of Scotland: An epidemiological review. Gastroenterology 1992;103:392-9

54 Moum B, Vatn MH, Ekbom A, et al. Incidence of inflammatory bowel-disease in Southeastern Norway-evaluation of methods after 1 year of registration. Digestion 1995;56:377-81.

55 Sawczenko A, Sandhu BK, Logan RFA, et al. Prospective survey of childhood inflammatory bowel disease in the British Isles. Lancet 2001;357:1093-4.

56 Armitage E, Drummond H, Ghosh S, et al. Incidence of juvenile-onset Crohn's disease in Scotland. Lancet 1999;353:1496-7.

57 Gillen CD, Andrews HA, Prior P, Allan, et al. Crohn's disease and colorectal cancer. Gut 1994:35:651-5.

58 Ekbom A, Helmick C, Zack M, Adami H-O. Increased risk of large bowel cancer in Crohn's disease with colonic involvement. Lancet 1990;336:357-9.

59 Mellemkjaer L, Olsen JH, Frisch $M$, et al. Cancer in patients with ulcerative colitis. Int J Epidemiol 1995;60:330-3.

60 Karlen P, Lofberg R, Brostrom O, et al. Increased risk of cancer in ulcerative colitis. Am J Gastroenterol 1999;94:1047-52.

61 Ekbom A, Helmick C, Zack M, et al. Extracolonic malignancies in inflammatory bowel disease. Cancer 1991;67:2015-9.

62 Heaton KW, O'Donnell L, Braddon FE, et al. Symptoms of irritable bowel syndrome in a British urban community: consulters and non-consulters. Gastroenterology 1992;102:1962-7.

63 Kennedy TM, Jones RH. Epidemiology of cholecystectomy and irritable bowel syndrome in a UK population. Br J Surg 2000;87: 1658-63.

64 Beckingham IJ. ABC of diseases of liver, pancreas and biliary system: gallstone disease. BM 1-13-2001;322:91-4.

65 Everhart JE, Khare M, Hill M, et al. Prevalence and ethnic difference in gallbladder disease in United States. Gastroenterology 1999:117:632-9.

66 Jorgensen T. Gall stones in a Danish population: fertility period, pregnancies, and exogenous female sex hormones. Gut 1988;29:433-9.

67 Suadicani P, Hein HO, Gyntelberg F. Genetic and life-style determinants of peptic ulcer: A study of 3387 men aged 54 to 74 years: The Copenhagen Male Study. Scand J Gastroenterol 1999:34:12-7.

68 Ahmed MEK, Arbab BMO, Homeida MMA. Social inequalities and health status in Western Germany. Public Health 1994;108:341-56. 